\title{
Engineering ethics of BIM and big data application in civil engineering
}

\author{
Jian Peng Xing ${ }^{1, a^{*}}$ \\ ${ }^{1}$ School of Management, Tianjin University of Technology, Tianjin, China
}

\begin{abstract}
As the second biggest economic entity, China is conducting the largest fundamental construction in the world. Architectural engineering is an important part of fundamental construction and China is witnessing its biggest construction industry in the world. With continuous scientific and technological development, China has stepped in the big data era, which produces higher requirements for architectural and civil engineering industry. Digital engineering construction technology, such as BIM technology, effectively improved design, construction, operation and maintenance of BIM technology, effectively improved the design, construction, operation and maintenance technology and quality of large construction projects. For the time being, China is encouraging engineering application and promotion of BIM technique in engineering construction industry. Fast scale enlargement and technical innovation not only produce new opportunities for change of construction industry, but also put forth strict requirements for engineering ethics in architectural and civil engineering construction.
\end{abstract}

\section{Introduction}

With the advent of the "data revolution" era, "data" has become an indispensable element in people's daily life, and it is also a production factor that promotes social development, causing new changes in social economic development, social structure and lifestyle. Through the in-depth processing and analysis of big data, data that is difficult to be collected and applied can be simplified, organized, and used better. Its technology has greatly broadened the scope and methods of information acquisition. It can quickly and accurately obtain useful information from a complex and huge database to help decision-makers make the most reasonable decisions.

In the new era, as one of the traditional industries of the national economy, the construction industry cannot continue relying on the traditional development model of rapid expansion. As the pace of comprehensive deepening of the construction industry continues to increase, it is urgent to use modern technological means represented by information technology to realize the transformation, upgrading and leapfrog development of my country's construction industry. The vigorous development of digital technology in the field of engineering construction represented by BIM technology has brought new opportunities for the improvement of large-scale construction engineering design, construction and operation and maintenance technology. The promotion of BIM technology can make construction management more efficient and promote the industry. Because the construction industry itself has the characteristics of long construction period, complex composition, high mobility, and many high-altitude operations, construction accidents often occur. Engineering ethics is still in its infancy in our country. It is often ignored or underestimated, lacks relevant experience, and has not formed the internal driving force and operating mechanism for the development of engineering ethics standards. Therefore, technological progress and development are also important for engineering ethics in civil engineering. Brings new challenges.

\section{The engineering ethics problems faced by civil engineering}

Construction engineering is an important representative of social development. It is not only a symbol of urban economic development, but also a symbol of scientific and technological progress. It always affects the survival and development of mankind. The quality of civil engineering works is not only related to people's personal and property safety, but also has a significant impact on social, political and economic activities. But while the construction industry is booming, its industry problems have also become increasingly prominent. One is the long-standing disadvantages of the construction industry, such as construction safety, construction quality and clean construction, etc. It is difficult to guarantee; second, as a traditional industry, the construction industry is lagging behind in the innovation and application of new technologies, with serious solidification thinking, and insufficient promotion and breadth of new technologies. , Leading to the slow development of new technologies in the field of civil engineering. On the one hand, the system 
and mechanism of my country's construction industry need to be further reformed and improved; on the other hand, the engineering ethics of civil engineering is also a factor that can not be ignored, so strengthening the construction of civil engineering engineering is also important to promote the high-quality development of the construction industry Initiative.

\subsection{Traditional engineering ethics in civil engineering}

It is undeniable that the core purpose of today's engineering activities is to pursue economic benefits. The core of the conflict between engineering profit maximization and ethics is that human activities must maximize profits and satisfy selfish desires.

Civil engineering construction is based on the construction contract, and is carried out in accordance with the design drawings and relevant standards and specifications. While this construction model has the advantages of clear responsibility, it also has disadvantages such as waste and inefficiency. Since the construction department, design department, construction department and supervision department are independent of each other, although nominally they all aim to achieve the unified construction goals of safety, quality, duration, and cost of project construction, in fact, a lot of waste will occur due to different interests.

In order to reduce the cost of the project, the construction department tends to win the bid with the lower price when bidding, and at the same time, it blindly reduces the construction period. The design department is not motivated to control the cost of the project because it is charged according to the project cost; in order to reduce its own responsibility, it tends to adopt a larger safety factor, thereby increasing the project cost. Since the construction department's bidding price is not enough to cover the construction cost, change negotiation has become an important means for it to turn losses into profits, and the current widespread problems of low design quality have created conditions for the implementation of these change negotiations. From the perspective of cost control, it is difficult for the supervision department to send highlevel supervision engineers, and the national policy level requires the supervision to take on too many responsibilities, making it exhausted to cope with it. It is only a construction quality and safety inspector, not a real consulting engineer.

\subsection{Engineering ethics of BIM and big data application in civil engineering}

The new construction mode represented by PPP, EPC, IPD, etc., is conducive to unifying and coordinating the rights and interests of all parties in the construction of the project, supplemented by modern information technologies such as BIM and smart construction sites, and industrialized construction technologies such as prefabricated construction technologies, becoming the direction of the modernization of the construction industry. However, relying solely on profit-driven and supervision cannot completely solve the existing problems in the industry, not only because the construction industry has a low level of industrialization and informatization in all industries, but also because of the strong creativity and low standardization of the construction industry. The entire industry is planning the design stage and construction management mainly depend on the role of practicing engineers, while in construction, it mainly depends on the quality and level of workers.

The application of modern information technology represented by BIM can solve the above problems to a certain extent. However, although the application of BIM can help improve the quality of design and construction, most of the design departments are not very motivated. The reason is that the initial application of BIM will reduce design efficiency, and the improvement of design quality will not bring obvious to the design department. Direct benefits. The enthusiasm of the construction unit to apply BIM is significantly higher than that of the design institute. In addition to increasing the bid winning rate, the key is that BIM can bring direct benefits to the construction department. The application of BIM can not only bring benefits such as quality improvement and cost reduction during the construction period, but also bring greater benefits from the perspective of the whole life cycle.

Although the application of BIM can partially solve the aforementioned problems, it also brings the following new problems.

\subsubsection{BIM model creation and sharing issues}

As the best means of information recording, the advantages of BIM technology are more reflected in the information integration throughout the life of a building. Only through multi-disciplinary and multi-stage integrated applications can the greater value of BIM be brought into play. However, in reality, the application of BIM pays more attention to its own value. The first problem faced is who builds the BIM model. The model created by the design department is unwilling to give to the construction unit, and the model of the construction department is unwilling to be included in the various professions. Sharing between the parties, resulting in repeated modeling; secondly, due to the unclear ownership and responsibilities in the sharing, all parties are unwilling to share. If the BIM model cannot clearly define ownership and responsibilities when it is passed and shared between participants, it will restrict the maximization of BIM value.

\subsubsection{Quality issues of BIM data}

The value of BIM is mainly reflected in two aspects. One is to solve the internal problems of the participating parties, and the other is to form data assets to lay the foundation for digital buildings and smart city applications. However, people often pay attention to the value of the first aspect and ignore the value of the second aspect. When quoting a project, the owner often requires the application of BIM but does not pay the corresponding fee, or only pays per 
square meter, and pays less attention to the quality of the model. During the construction process, due to the lack of an inspection and acceptance mechanism like a physical project, the quality of the final delivered model varies greatly, and it is difficult to meet the needs of further application and big data analysis.

\subsubsection{Security issues of BIM data}

Civil engineering drawings themselves will become tools for criminals and terrorists to commit crimes. Because BIM holographic description of engineering objects, it has richer and more complete engineering information, and its electronic attributes determine the security of BIM data is more important.

\subsubsection{The redistribution of industrial profits brought about by BIM applications}

The reduction of errors, omissions and deficiencies, the simple and accurate calculation of the engineering quantity, and the transparency of the construction process will all touch the interests of the construction unit and greatly reduce the profitability of the construction unit.

\section{Promote engineering ethics of civil engineering}

\subsection{The anomie of contemporary engineering ethics}

During the concrete pouring process of the BGY project, the construction staff of a labor service company collapsed the formwork. The collapsed area was about 300 square meters. Some of the workers on the site were buried by the formwork and steel pipes. After self-rescue on the site, 1 person died and 2 people were seriously injured. The consequences of minor injuries to 7 people have caused a direct economic loss of 2.13 million yuan. After investigation, the direct cause of the accident was that the construction of some main beams and secondary beams was not carried out in accordance with the principles and regulations, which led to the instability of the bottom of the beam; the indirect cause of the accident was that the construction department blindly rushed the schedule and shortened the construction period, and failed to strictly implement the guarantee in accordance with relevant regulations Measures for engineering quality and safety. The organization of the construction department is not standardized and the safety system is not implemented. The supervision department did not supervise in place, and the hidden safety hazard of the project was not discovered in time. The labor subcontracting department did not earnestly implement the main responsibility for safe production.

In this case, the collapse of the formwork caused many casualties, not only due to the engineering technology itself, but also due to human factors, among which engineering ethics issues were the dominant factor. Engineering ethics is the sum of all moral issues in engineering construction activities. With the vigorous development of construction engineering, human ethics and social ethics are facing various difficulties and challenges in engineering construction. Therefore, a series of problems that occur in engineering can no longer be solved by technology alone, but by methods based on engineering ethics.

Table 1. Division of engineering ethical responsibility.

\begin{tabular}{|c|c|c|}
\hline Participants & Ethical issues & Violated ethical regulations \\
\hline Construction department & $\begin{array}{c}\text { Serious lack of management responsibility: } \\
\text { arbitrarily shorten the construction period and } \\
\text { conceal the risk of some projects that have not } \\
\text { been reported }\end{array}$ & $\begin{array}{c}\text { Obligation: Active responsibility to } \\
\text { comply with standards and determine } \\
\text { project goals }\end{array}$ \\
\hline Construction department & $\begin{array}{c}\text { Serious lack of safety responsibility: failure to } \\
\text { strictly implement safety production } \\
\text { management systems and measures; } \\
\text { inadequate management, education and } \\
\text { training of on-site operators }\end{array}$ & $\begin{array}{c}\text { Professional responsibility: complete } \\
\text { the job objectively and determine the } \\
\text { engineering constraints }\end{array}$ \\
\hline Labor subcontracting department & $\begin{array}{c}\text { Lack of management and safety } \\
\text { responsibilities: safety education and training } \\
\text { are not in place; technical exchanges are not } \\
\text { carried out as required; on-site operators are } \\
\text { not urged to construct in accordance with the } \\
\text { technical requirements specified in the plan }\end{array}$ & $\begin{array}{c}\text { Role responsibility: grasp the work } \\
\text { content of the division of roles, and } \\
\text { assume the corresponding work } \\
\text { responsibilities }\end{array}$ \\
\hline Supervision department & $\begin{array}{c}\text { Lack of supervision responsibility: inadequate } \\
\text { supervision of projects with higher risks }\end{array}$ & $\begin{array}{c}\text { Professional responsibility: complete } \\
\text { project supervision as a third-party } \\
\text { object }\end{array}$ \\
\hline
\end{tabular}




\subsection{Solutions to engineering ethics issues in the application of BIM and big data in civil engineering}

\subsubsection{Innovative BIM model creation and sharing mechanism}

On the one hand, as the country promotes the development of prefabricated buildings and the popularization of general project contracting, whole-process consulting, etc., the problem of model creation and sharing between design and construction units has changed from an external problem to an internal problem and is easy to solve; On the other hand, through cloud technology or blockchain technology, the model can be stored locally in each of the participants, and each has complete property rights. The project cloud can be established between the participants, and the sharing mechanism should be established as needed. In addition, BIM should also be emphasized. Data asset value, clear pricing and payment, and clear model creation and sharing responsibilities to mobilize the enthusiasm of all parties involved in the construction.

\subsubsection{Pay attention to BIM model data quality}

Through the application of digital technologies such as BIM, a digital building can be constructed while building a physical building. Digital twins, visualized operation and maintenance, etc. are used to realize the digitization, networking and intelligence of the building, which also lays the foundation for the construction of smart cities. Model data quality is the top priority. The solution is to clarify model creation responsibilities through contracts and payment; establish modeling standards; establish model verification and review mechanisms; hire professional institutions to conduct model quality inspections.

\subsubsection{Attach importance to BIM model data security by surpassing the importance of engineering drawings}

The copying and dissemination of BIM models is far more convenient than engineering drawings, and the details of engineering descriptions are higher. Therefore, the security of computer systems, the storage and delivery of models, and the storage and use of models should be clearly defined. Secrecy projects shall be managed strictly in accordance with secrecy regulations.

\subsubsection{Establish a mutually beneficial and win-win industrial ecological environment}

Through the innovation of construction methods such as IPD (Integrated Project Delivery Mode), the project construction participants can share risks and benefits, and all parties can achieve energy saving and consumption reduction through the application of BIM and other technologies, reduce project costs, and realize according to the new benefit distribution mechanism A win-win situation for all parties.

\section{Conclusion}

It is undeniable that the core purpose of today's engineering activities is to pursue economic benefits. The pursuit of maximization of interests in contemporary engineering activities is rooted in the "self-interest principle", and ethics and morality are the "altruistic principle". This has caused a certain conflict between engineering activities and ethical norms. In the process of urban construction in the future, the "visible" city must be built as the city's appearance, and the "invisible" city must be built as the soul of the city.

In the data age, with the development and diversification of technical means, civil engineering engineers are given more responsibilities and face more challenges. Civil and construction engineers must not only have a strong will to innovate and apply new technologies, and continue to deepen reforms and technological progress, but also uphold good engineering ethics and give full attention to the importance of engineering ethics.

\section{References}

1. He Silin. Research on the Ethical Issues of Big Data Technology [D]. Chengdu University of Technology, 2017.

2. Zhao Mingyi, Jiang Xiaohui. The origin of utilitarianism in the anomie of contemporary engineering ethics and its solutions [J]. Journal of Shenyang Institute of Technology. 2017. 13(4).

3. Shao Yuanhang. The application of BIM technology in civil engineering under the background of big data [J].China High-tech, 2019(01):101-103.

4. Pan Jiayi, Zhao Yuanyu. Analysis of obstacles to the development of BIM in China's construction industry [J]. Journal of Engineering Management, 2012, 26(01):6-11.

5. Yi Yongqing. "Urban Development from the Perspective of Ethics" Symposium was held in Beijing [J]. Journal of Hunan City University, 2014, 35(06): 106.

6. Cai Shiran, Zhang Tong. Natural dimensions and sustainable design strategies of green smart buildings [J]. Urban Architecture, 2018(16):19-23.

7. Li Jiulin. Research and application of BIM technology in large-scale construction general contracting projects [M]. Beijing: China Construction Industry Press, 2014.

8. Li Jiulin, Wei Lai, Wang Yong, et al. Smart construction theory and practice $[\mathrm{M}]$. Beijing: China Construction Industry Press, 2015. 